\title{
Coping with a quake
}

\author{
By Linda B. Johnson
}

Head, Government Publications Dept. San Jose State University

\section{and Jeff Paul}

Head, Media Department

San Jose State University

\section{Communication is the key to the first 48 hours after an earthquake.}

$\mathbf{A}$ year ago, October 17, 1989, at 5:04 p.m. in Bay Area libraries, we were reeling with one of the most forceful and frightening earthquakes in recent memory. Immediately after the 7.1 shaker, we only wanted to shut down our libraries, get home, find our family and friends, and begin to pick up the pieces.

It was only days and weeks later that we had the luxury and inclination to stop and reflect on what has affectionately been called "the pretty big one." Through this experience we have come to realize that in any disaster situation, the responses made during the first few hours will have a decisive effect on all subsequent actions and in many cases the ultimate success of the recovery. And without doubt, the keystone in any response strategy is communication - the very basic ability to be able to provide information to and from individuals, groups, and organizations effectively.

As information professionals, we librarians are skilled at communicating; it is our business, one of the things we do best, the cornerstone of our profession. Nevertheless, in the recent Loma Prieta earthquake, we discovered that in emergencies our communication skills and level of their preparation require, to say the least, refinement.

Our communication actions and those of librarians at other campuses constituted a mix of successful and not so successful responses. This article briefly outlines some of those responses and then builds upon them to offer suggestions for the re- grettable but inevitable next emergency.

In California, this emergency will most likely be an earthquake. The latest estimates from the U.S. Geological Survey's Working Group on California Earthquake Predication Evaluation Council predict a $67 \%$ chance of a 7 or greater magnitude earthquake in the San Francisco Bay Area within the next 30 years. ${ }^{1}$ In other localities, different emergencies loom larger. A startling and sobering statistic is that, according to a Florida study, in the last five years (1982-1987), 68.8\% of academic libraries experienced some sort of damage caused by an emergency situation. ${ }^{2}$

\section{Reality of the situation}

Communication is so essential for two reasonsone psychological, the other physical. As for the psychological, the unknown is vastly more frightening and unmanageable. A known calamity at the very least has a beginning with which we can begin to cope mentally; then a middle and end that we can anticipate and work towards.

${ }^{1}$ Pete Carey, "Odds for Big Quake Rise," San Jose Mercury News, 20 July 1990, 22A.

${ }^{2}$ John N. DePew, Statewide Disaster Preparedness and Recovery Program for Florida Libraries (Urbana, Ill.: University of Illinois, Graduate School of Library and Information Science, Occasional Paper no. 185, February 1989), 8. 
As a colleague noted, seeing the actual damage on the upper floors of our library was oddly comforting. The reality, no matter how bad, was a welcome relief to any number of imagined horrors. "Seeing is believing" also proved true for students serving on the Reference Information Desk who were intentionally taken to the closed floors to view the damaged stacks. In this way, many of their fears were laid to rest, enabling them to convey a higher level of assurance to patrons.

As for the physical reality, in a purely logistical sense, it is like tackling a shadow to fix an undefined problem. Where is it? What is it? What can we do? Knowledge has to be the first step on the road to a solution; communication provides the road signs along the way.

On that afternoon the immediate power and telecommunication failures cut us off from those staff members who had left the campus or had never been in that day, as well as the community at large. On-site decisions were effectively handled by remaining staff and administrators, but once they left the campus, communication linkages further deteriorated.

\section{One picture is worth ...}

Let's begin on a positive note with the more effective communication techniques. It is surely no accident that some of these addressed more than one of the five senses. At San Francisco State University, staff members immediately put on bright orange vests and used bullhorns to direct people out of the building and off the campus quickly.

Photographs were used to illustrate the damage and accompany verbal or written reports. In our library it was difficult to justify the immediate closing of the damaged stack areas to public access during one of the busiest times of the academic year. Since patrons did not see any disorder on the accessible floors, they were hard to convince that the action was anything less than capricious. The colorful and vivid snapshots of the twisted shelving and spilled books quickly silenced complaints. In fact, the photo display at the library entrance was immediately mobbed and the picture boards at the reference desk were a focus of attention for students and users. We discovered that relatively few pictures were worth much more than any number of words of explanation.

Other successful communication techniques were an outgrowth of staff quick-wittedness and composure under intense pressure. For instance, the staff members in the building at the time of the quake made a speedy and accurate assessment of the severity of the situation and then personally communicated the need to vacate the building to patrons. Even allowing for some glitches to be

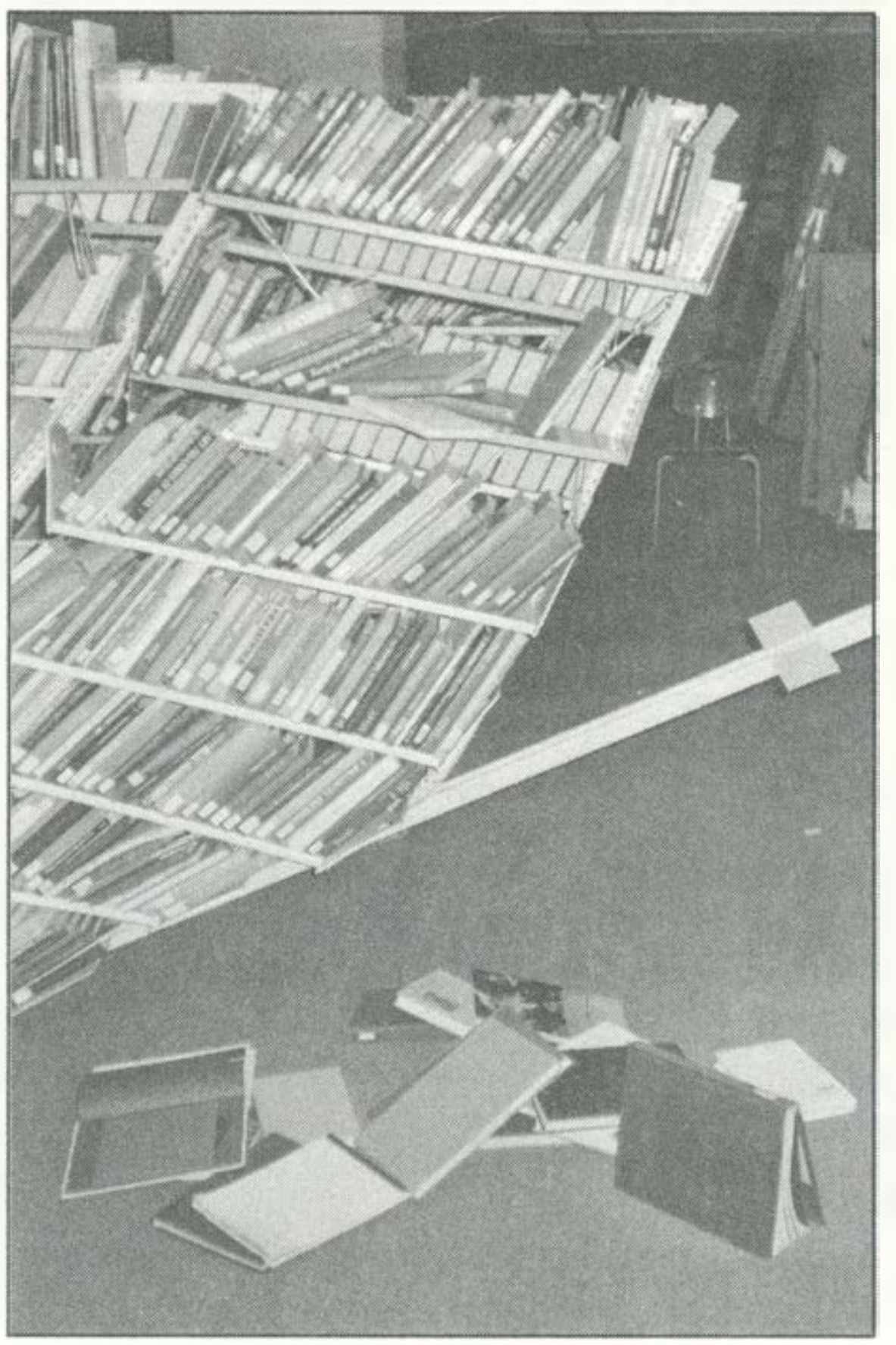

Damage to upper floors of Clark Library, San Jose State University.

discussed later, this resulted in a reasonably trouble and injury-free evacuation of the main library building. At another campus, an evacuation was handled even more smoothly as they followed the procedures laid out in an existing Disaster Preparedness Plan.

Then, despite intermittent phone service, vendor telephone numbers buried in office files, and an empty, eerie, potentially dangerous building, administrators immediately contacted a shelving vendor. In many libraries, the damage was centered around the book stacks themselves and did not pose serious building structural problems. Therefore, early consultation with a local library shelving supplier was the most crucial step in assuring a speedy recovery and resumption of services.

\section{Communication networks}

During the day following the quake, the key to an effective response at one campus was a very hierarchical communication system. The trickledown, bubble-up theory of communication worked well as information flowed down and up the organization's structure from the administrative staff to the section heads to individual unit managers to staff and back up again. To gather and exchange 


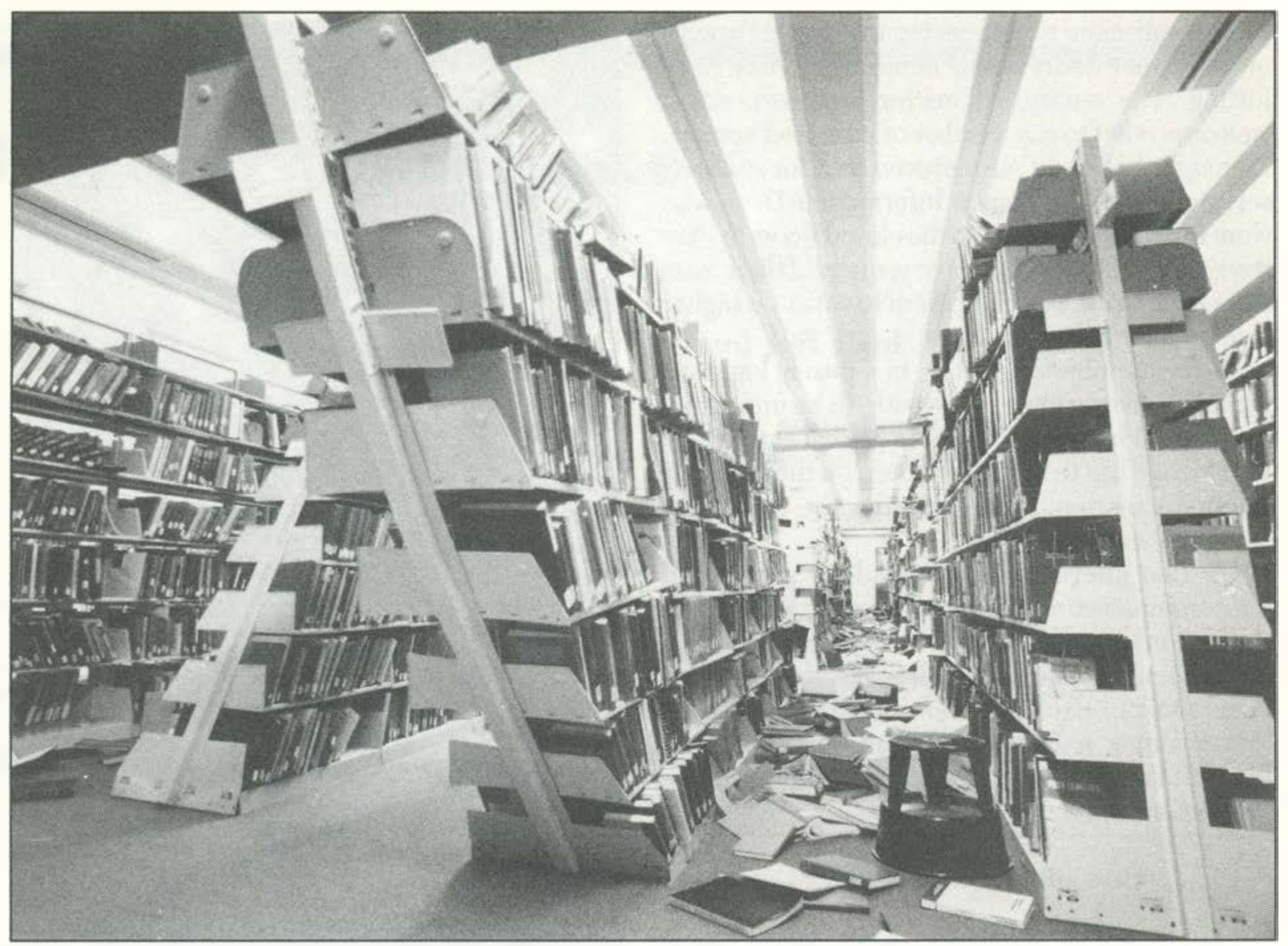

More damage to upper floors of Clark Library, San Jose State University.

information, there was a cycle of selected staff gettogethers augmented by the issuance of administrative bulletins. Recovery then proceeded based on the most accurate assessment of the situation.

To communicate with the wider university and surrounding communities, campus information dissemination groups (information offices, emergency operations centers) generally helped to spread the word. In many cases they were responsible for providing notices to the local newspapers, broadcasts on the local radio stations, and television announcements.

Libraries often furnished recorded announcements on public service telephone lines with the latest information on their status. For patrons who did make it to campus, signs posted on library doors indicated the situation.

Interestingly, in some cases automation provided an unexpected communication avenue. At the national level RLIN and OCLC, with varying degrees of detail and results, were able to indicate whether interlibrary loan service at a particular institution had been interrupted. If the library had closed, RLIN indicated this along with the expected date of reopening. Locally, certain online card catalogs were also helpful. Some libraries, with service desks open while their actual bookstacks were closed, had access to the MELVYL
(University of California) online catalog and could determine for patrons if the material was available at Berkeley. An unnecessary trip for the patron was thus avoided and additional crowding at an already overtaxed library was prevented.

A subtle, soon forgotten but crucial aspect of personal recovery was the need for each of us to tell our story - where we and our family were and what happened to us during those endless 15 seconds and the subsequent hours. We now realize that for library staff as well as returning patrons, this was a truly cathartic and healing process that allowed us all to come to terms with the experience and return to normal.

This should not come as a surprise since it is a commonly recognized fact that survivors of traumatic events find such a retelling, venting, and sharing extremely therapeutic. Most recently this has been documented by James Pennebaker's study of survivors of the Loma Prieta earthquake who, he found, suffer from post-traumatic stress syndrome. According to Pennebaker, "Those people who are the most distraught report thinking about the earthquake a lot, but not talking about it." He further noted that "the best way to get out of it is to not try to suppress the thoughts. Confront them by writing about them and talking about them in a reflective manner: 'Why am I having these 


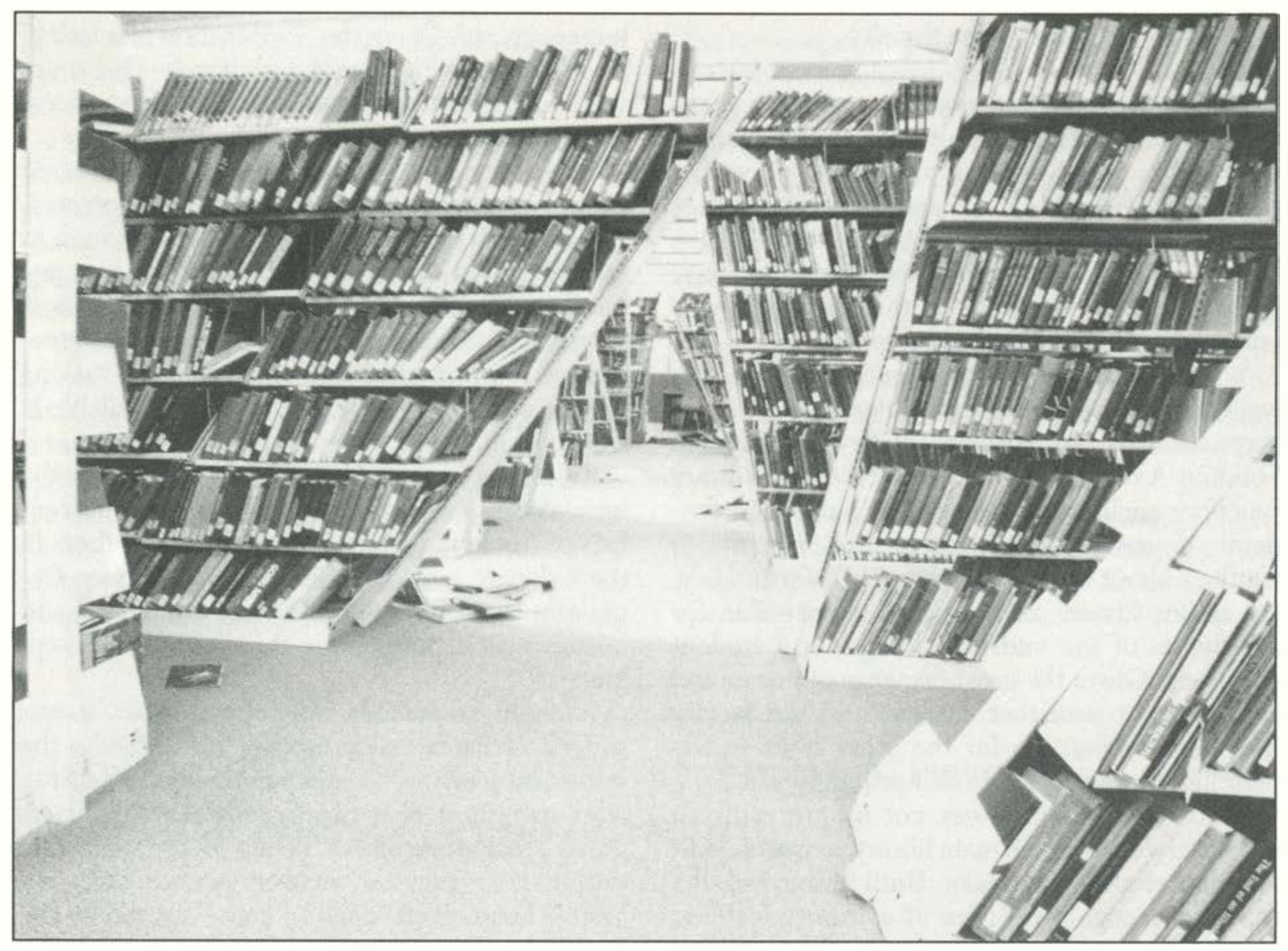

Still more damage to upper floors of Clark Library, San Jose State University.

thoughts, what does it say about the event, about my emotions."'3

\section{Useful lessons}

In many cases we actually learned more from the less successful strategies. Some were closely related to the successful strategies but just did not work; others were techniques that were entirely overlooked at particular libraries.

During the evacuation in some libraries the noise of the alarms-designed to clear the building quickly - made it difficult to hear if any patrons were trapped inside.

A 35-minute video was shot at San Jose State University to document such internal damage as swayed bookstacks and tipped print cases; unfortunately it did not help to secure funds from the Federal Emergency Management Agency (FEMA). Videotape, like photographs, can clearly document the severity of a situation and be used to further disseminate the news. The tape was used in a campus news broadcast about the earthquake on

${ }^{3}$ James Pennebaker, Opening Up: The Healing Power of Confiding in Others (N.Y.: William Morrow, 1990). the local PBS television station and shown to visiting engineers studying the earthquake damage.

Telephone trees and lists of staff to be called were also problematic. Some staff had to return to the campus to learn of recovery plans since home telephone numbers, listed and unlisted, were only accessible through unavailable office files. Consequently, library staff and the public were dependent on announcements in the media (radio, television, newspapers) for the critical information about whether or not the campus was open. And the local media paid scant attention to the university situation, given the need to focus on the more dramatic and gripping tragedies all around the Bay Area. To further complicate the situation, institutional announcements that did make it into the media generally did not include the status of the library.

Finally, some institutions were unable to establish and maintain systematic and consistent communication networks. Often, staff on the frontline public service desks did not receive news of the latest damage evaluation, expected date of reopening, or status of neighboring libraries. Adding to the confusion and consternation of staff and patrons, unofficial, often distorted, and frequently inaccurate news rushed into the void created by the lack of official information. 


\section{Voice of authority}

In the second category of completely overlooked communication tools, one of the primary ones at San Jose State was an existing university public address system located at the center of campus but used only as a bell tower. It could have been put into service by the Emergency Response Team to direct evacuation of the central campus area immediately following the quake.

It is almost certain that such a note of authority would have prevented the major fiasco of the evacuation of our auxiliary library and storage building. A shared tenancy facility with non-library functions such as the Computer Center and academic departments seemed to lead naturally to conflicts about who was in charge. Unfortunately, the senior library staff member responsible for evacuation of the entire building was a student employee. Given the great disparity of power and authority between that student and the faculty members responsible for the other units in the building, it was inevitable that problems arose.

Thus, this building was not secure until an administrator from the main library arrived at least 40 minutes after the quake. Until her arrival, the lack of a recognized figure of authority fostered garbled and unheeded communication between individuals sharing the building.

A final overlooked communication link led to minor evacuation problems in the main library. In the understandable rush to leave the building, many patrons did not think or were not reminded to take their belongings. They then found themselves outside without money, keys, or other essentials. Staff members had then to reenter the potentially dangerous library to rummage in the dark and retrieve their belongings.

\section{Better next time}

Drawing upon these experiences, we have made a preliminary summary of necessary communication skills for a disaster situation. First, an effective evacuation of a building requires a number of essential steps. Big Brother fears notwithstanding, a building-wide public address system provides a pervasive "voice of authority" that can more clearly direct the desired group action. This is even more critical for those buildings occupied by a number of separate administrative units and all buildings during non-peak hours when only a skeleton crew is present. To improve control over the evacuation, key staff members can communicate with each other by walkie-talkies.

Unless the persons in charge display some obvious signs of authority such as a P.A. system, identification badges, armbands, colorful clothes, or bullhorns, their leadership role will not necessarily be recognized. Given the combination of a lack of clearly responsible people and damage that is not readily apparent, many patrons will refuse to leave or cooperate in any way.

Also, there is no guarantee the disaster will occur when key administrators or line staff are present. Thus, all staff right down to the newly hired student employee need to be aware of procedures to protect people, collections, and facilities as much as possible. Furthermore, there needs to be agreement as to who is ultimately responsible for making the big decisions depending on who is available at the time.

To assure communication among staff after the immediate disaster, all employees need current lists of the home telephone numbers of others in their department. And since public phones frequently come back online before residential and business ones, money for these should be kept handy.

As soon as possible after the disaster, it was suggested that one staff member be assigned as the information officer or public relations specialist to administer and disseminate official information. Some acknowledgement needs to be made that during emergency and recovery periods, there is a greatly heightened "need to know" caused by the demands of uncertainty.

Faculty and campus administrators should be contacted to clarify any restricted access to the collections and resources so they can adjust assignments and requirements for their students. If the collection will be inaccessible for an extended period of time, reciprocal borrowing and/or use arrangements with local institutions need to be established.

To facilitate such agreements and the sharing of expertise, supplies, recovery skills, and general moral support, libraries need to fashion bare-bones networking linkages so that at least minimal contact is maintained. Perhaps a central office located at a designated library could serve as a communications hub for the latest information on libraries.

Finally, there is an urgent need to practice building evacuation, especially during evening and weekend hours when minimal staffing exists. Such sessions will quickly highlight flaws in procedures and allow for adjustments.

\section{Conclusions}

Painful and traumatic as it was to get through the quake, unending aftershocks, and first few days of uncertainty, we gained hard-won insights. These will make our emergency communication techniques and responses to future disasters better.

One librarian from the University of California, Santa Cruz, remarked that there is a renewed sense 
of fellowship coming from the shared experience. Such fellowship has lead to tangible gains in library networking. For instance, at the November 1989 California Library Association (CLA) Convention, almost every meeting included a lengthy sharing session of what happened as well as the responses. Valuable informal contacts and specific formal groups such as the CLA Ad Hoc Earthquake Committee have been formed.

Another example is an LSCA grant spearheaded by the South Bay Cooperative Library System. Encompassing multi-type libraries, this grant proposes to fund workshops in which teams from special, public, academic, and school libraries create model disaster plans. The primary goals are to: "1. Improve the capability of Bay Area libraries of all types to respond to and recover from natural disasters, and 2. Establish a framework for regional disaster cooperation by libraries of all types."4

We have touched upon just some of the communication techniques which will undoubtedly be expanded and added to by these and other networks. As we and colleagues continue to explore these issues, emergency communication will become an integral part of what makes us "information professionals."

Author's note: Library staff at the following campuses were consulted: University of California at Santa Cruz and Berkeley; California State University at San Jose and San Francisco; and Stanford University.

${ }^{4}$ South Bay Libraries Disaster Training Project. California State Library, Library Services and Construction Act, 1990/91, Title III, Library Cooperative Projects Application, May 30, 1990.

\section{Ornamental frieze discovered during Missouri Historical Society's renovation project}

The Missouri Historical Society's efforts to preserve the historic character of the old United Hebrew Temple, which will house the Society's new library and research center, have been rewarded with the discovery of a handsome Byzantine-style frieze.

The frieze, preserved under plaster board and wire mesh, was uncovered at the base of the temple's 30 -foot dome. After restoration, the frieze will complement the reading room, the heart of the new library.

The $\$ 9.1$ million project, on the western edge of Forest Park in St. Louis, was begun last year. When completed in late 1991, the renovated structure will house the Missouri Historical Society's collections of books, manuscripts, maps, newspapers, photographs, prints, and video material. Included are the private papers of Thomas Jefferson and Charles A. Lindbergh, the original journals from the Lewis and Clark expedition, and documents from the North American fur trade and the French and Spanish colonial regimes. To make way for three floors of stack space for the library collections, the old heating system, classrooms, and seating were removed from the old building and a new 54,000 square foot conservation annex is being added to the south of the old building.

The United Hebrew Temple was purchased by the History Museum Subdistrict of the Metropolitan Zoological Park and Museum District in February 1989 so that the 65-year-old structure could be reconditioned for use by the Missouri Historical
Society. The Byzantine temple was originally designed by the St. Louis architectural firm of Maritz and Young, collaborating with Gabriel Ferrand, for the United Hebrew Congregation. It was recently placed on the National Register of Historic Places as part of the Wydown-Forsyth historic district.

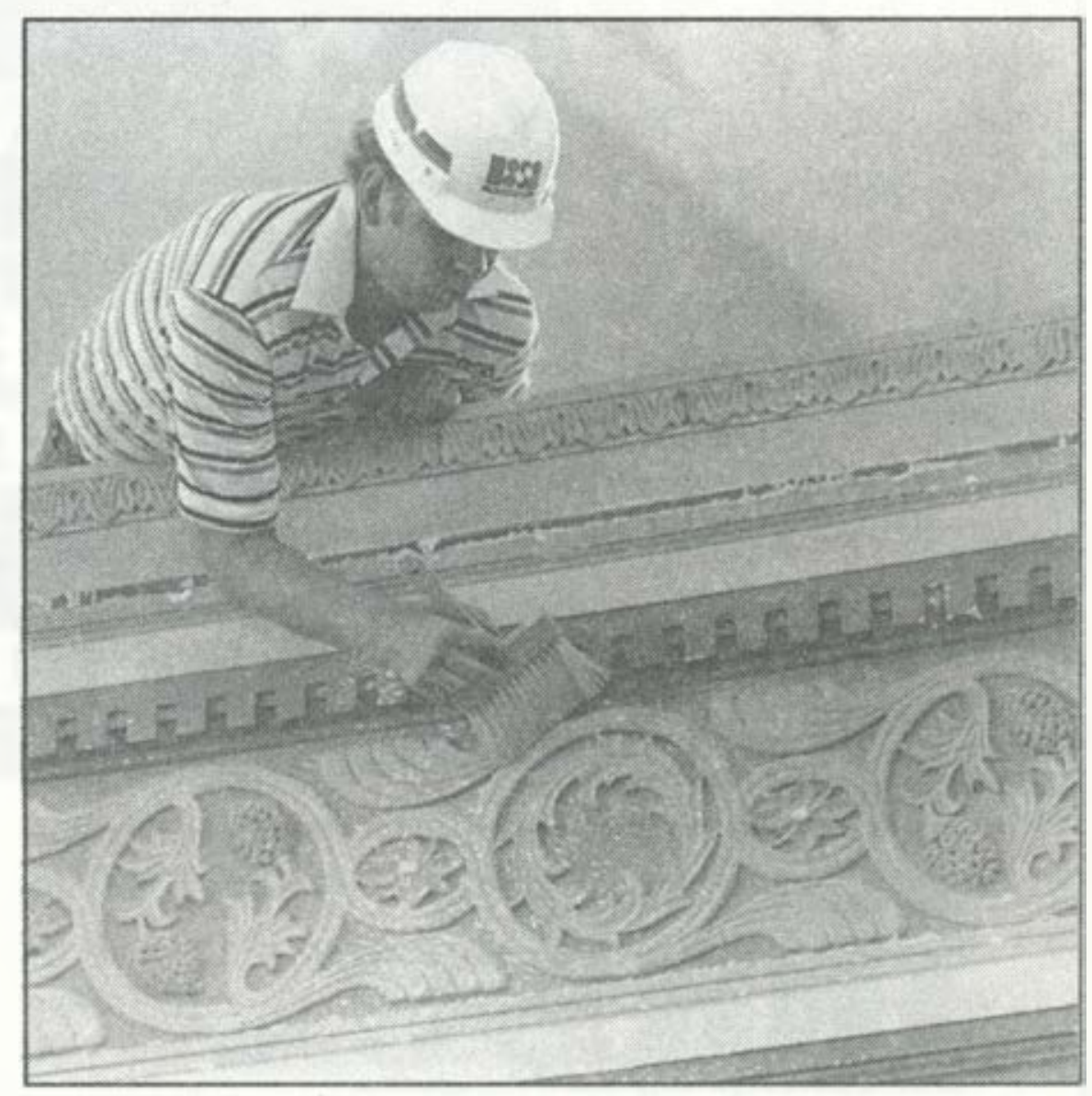

Dan Kloeppel, project superintendent for BSI of St. Louis, cleans a frieze at the former United Hebrew Temple now under renovation by the Missouri Historical Society for its library and research center. 


\section{ACQUISITION PERSPECTIVES}

6. Book House is in its fourth generation of automation. Our custom software allows us the flexibility to accept orders generated through your computerized system or in the mail. Our policy is to develop a working compatibility with the automated system in your library to facilitate receiving orders, transmitting open order reports and invoices electronically.

Let's explore interfacing your automation with ours.

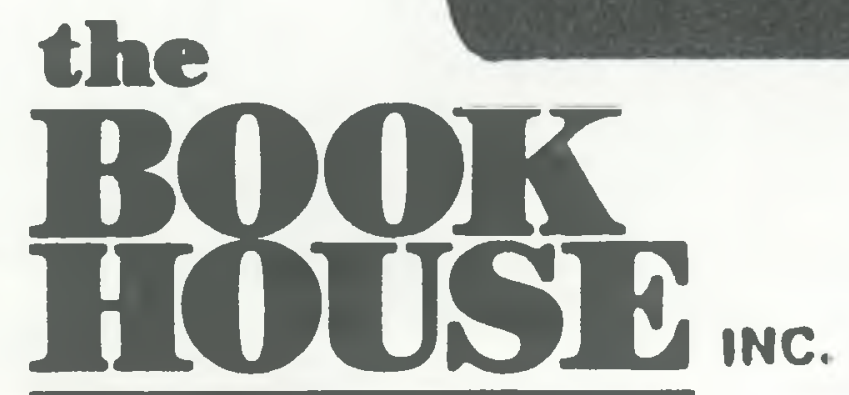

Since 1962

JORBERS BEAVNO LURARIES WITH

ANY DOOK IN PRINT SINCE 1082

208 WEST CHICAGO STREET

JONESVILLE, MICHIGAN 49250

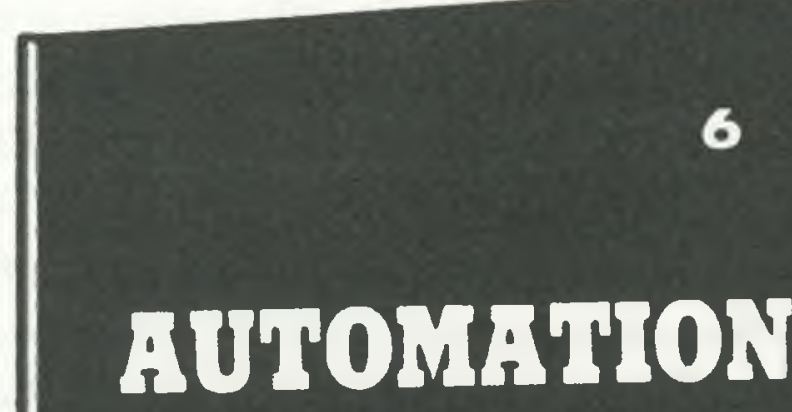

MBRARY - VHNDOR INTHERCE

BOOK HOUSE

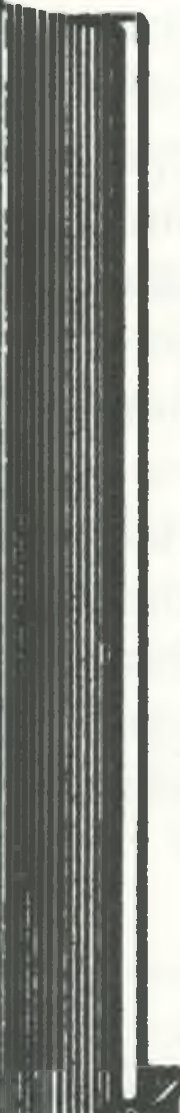

I ANY BOOK IN PRINT

2 COMPLAI DATHAR

3 OPHN ORDAR RPPORTS

4

ACCURATH BOOR

DमHWH:?

\section{STRNDTHE ORDARS}

\section{Call or Write TODAY}

$1 \cdot 800 \cdot 248 \cdot 1146$

FAX: $517 \cdot 849 \cdot 9716$ 